\title{
A Comparison of Physiological Response to Incremental Testing on Stationary and Dynamic Rowing Ergometers
}

\author{
Marie Boland, Nora May Crotty, Nick Mahony, Bernard Donne, and Neil Fleming
}

\begin{abstract}
Purpose: The purpose of the current study was to compare responses to graded exercise testing (GXT) on 2 popular commercial rowing ergometers. Methods: A cohort of 23 subelite male rowers (age 20 [2] y, height 1.88 [0.06] m, body mass 82.0 [8.8] kg) performed a GXT on both stationary (Concept2 [C2]) and dynamic (RowPerfect3 [RP3]) rowing ergometers. Physiological responses including oxygen consumption $\left(\mathrm{VO}_{2}\right)$, heart rate $(\mathrm{HR})$, blood lactate concentration $(\mathrm{BLa})$, stroke rate (SR), and minute ventilation (VE) were recorded. BLa data were plotted graphically and anaerobic threshold was identified using the $\mathrm{D}_{\text {max }}$ method. Workload, $\mathrm{HR}$, and $\mathrm{VO}_{2}$ at $\mathrm{D}_{\max }$ were interpolated. Physiological responses at maximal exercise and at $\mathrm{D}_{\max }$ were compared, along with response across a discrete range of submaximal workloads. Results: At maximal exercise, no significant differences in $\mathrm{HR}, \mathrm{VO}_{2}$, or BLa were observed $(P>.05)$; however, $\mathrm{VE}_{\text {peak }}$ was significantly higher during RP3 tests $(T=2.943, P<.05)$. No significant differences in $\mathrm{HR}, \mathrm{VO}_{2}$, or $\mathrm{BLa}$ at $\mathrm{D}_{\max }$ were observed $(P>.05)$. When comparing across submaximal workloads, $\mathrm{HR}$ was significantly higher with the RP3 at 2 distinct workloads $(210$ and $240 \mathrm{~W} ; P<.05)$, while SR was higher during RP3 testing at all workloads $(F=56.7, P<.05)$. When SR was fixed as a covariate, the effect of ergometer on HR response was not significant. A significant workload by ergometer interaction effect was observed for SR with higher data recorded on the RP3 $(F=3.48$, $P<.01)$. Levels of agreement for GXT-derived measures of anaerobic threshold $\left(\mathrm{D}_{\max }\right)$ were deemed unacceptable. Conclusions: These results indicate that while some differences in HR and VE response were observed between ergometers, these differences were a result of SR alterations between ergometer type. While no differences in response at $D_{\text {max }}$ were observed, the poor levels of agreement between ergometers suggests that prescription of GXT-derived threshold for training should ideally be specific to the rowing ergometer upon which the test was performed.
\end{abstract}

Keywords: exercise physiology, lactate, oxygen uptake, heart rate, rowing ergometry

Ergometers are commonly used by rowers as supplementary training tools, especially during winter months. ${ }^{1}$ Laboratory-based ergometer testing is also used for the purposes of training prescription, monitoring, and high-performance selection. ${ }^{2}$ As rowing is an endurance sport, aerobic capacity is a significant determinant of successful rowing performance, accounting for up to $70 \%$ of an athlete's energy expenditure over a 2000 -m event. ${ }^{3}$ Key physiological parameters, including peak aerobic capacity $\left(\mathrm{VO}_{2}\right.$ peak), blood lactate concentration (BLa) across load and oxygen consumption $\left(\mathrm{VO}_{2}\right)$, and heart rate (HR) at anaerobic threshold, can be measured using a graded exercise testing (GXT). These data can subsequently be used to prescribe individualized HR and/or load-based training zones.

Traditionally, stationary ergometers, such as the Concept2 (C2), have been favored for laboratory-based testing. In a stationary ergometer, both the flywheel and footrests are fixed to a frame and only the operator and seat move relative to the ground. Dynamic ergometers have been developed to more closely replicate the movement dynamics and energy costs associated with onwater rowing. ${ }^{1}$ In a dynamic ergometer, such as the RowPerfect, the flywheel and footrests are both mounted to a movable unit, allowing the rower and unit to move relative to each other along sliding rails (see Figure 1). This dynamic action is similar to onwater rowing during which the boat slides underneath the rower. ${ }^{4}$ Increasingly competitive rowers are now training on dynamic ergometers to obtain better real-water "feel."

Boland is with the Human Performance Laboratory, School of Medicine, and Crotty, Mahony, Donne, and Fleming, the School of Medicine, Trinity College Dublin, Dublin, Ireland. Boland (maboland@tcd.ie) is corresponding author.
Evidence that dynamic ergometry more closely simulates the movement dynamics of on-water rowing has been inconsistent. Significant differences in leg muscle recruitment patterns, handle force, and stroke length have been reported when comparing onwater rowing with both stationary and dynamic ergometry. 5,6 Other studies have directly compared the 2 ergometer types. Findings of longer stroke length and higher mean force generation per stroke ${ }^{7}$; increased peak handle force, rate of force generation, and stroke ratio $^{8}$; and reduced stroke rate $(\mathrm{SR})$ with increased mean and maximum force development ${ }^{9}$ for stationary ergometry have been reported. These studies support a difference in kinematics between stationary and dynamic ergometry but suggest that neither form provides a suitable alternative to on-water rowing. ${ }^{6}$

Studies describing physiological responses to different forms of rowing have been similarly inconsistent. Comparing stationary ergometry with on-water rowing, Vogler et $\mathrm{al}^{2}$ observed no differences in physiological responses $\left(\mathrm{HR}, \mathrm{BLa}\right.$, or $\left.\mathrm{VO}_{2}\right)$ at submaximal workloads. Similar findings have been reported in studies directly comparing stationary with dynamic ergometry. ${ }^{9}$ In addition, Mahony et $\mathrm{al}^{10}$ observed no significant differences in physiological responses ( $\mathrm{HR}, \mathrm{BLa}, \mathrm{VO}_{2}$, and minute ventilation [VE]) to GXT performed on fixed and free iterations of the RowPerfect.

Conversely, Benson et $\mathrm{al}^{8}$ did report significant differences in physiological responses among male rowers performing a 1000-m time trial on stationary and sliding $\mathrm{C} 2$ models. Dynamic ergometry was associated with higher $\mathrm{VO}_{2}$ costs and lower efficiency indices. Rossi et $\mathrm{al}^{11}$ directly compared performances on stationary and dynamic $\mathrm{C} 2$ models. They observed increased $\mathrm{HR}$ and $\mathrm{VO}_{2}$, as well as reduced BLa accumulation on the dynamic ergometer. They concluded that results obtained from laboratory-based testing 

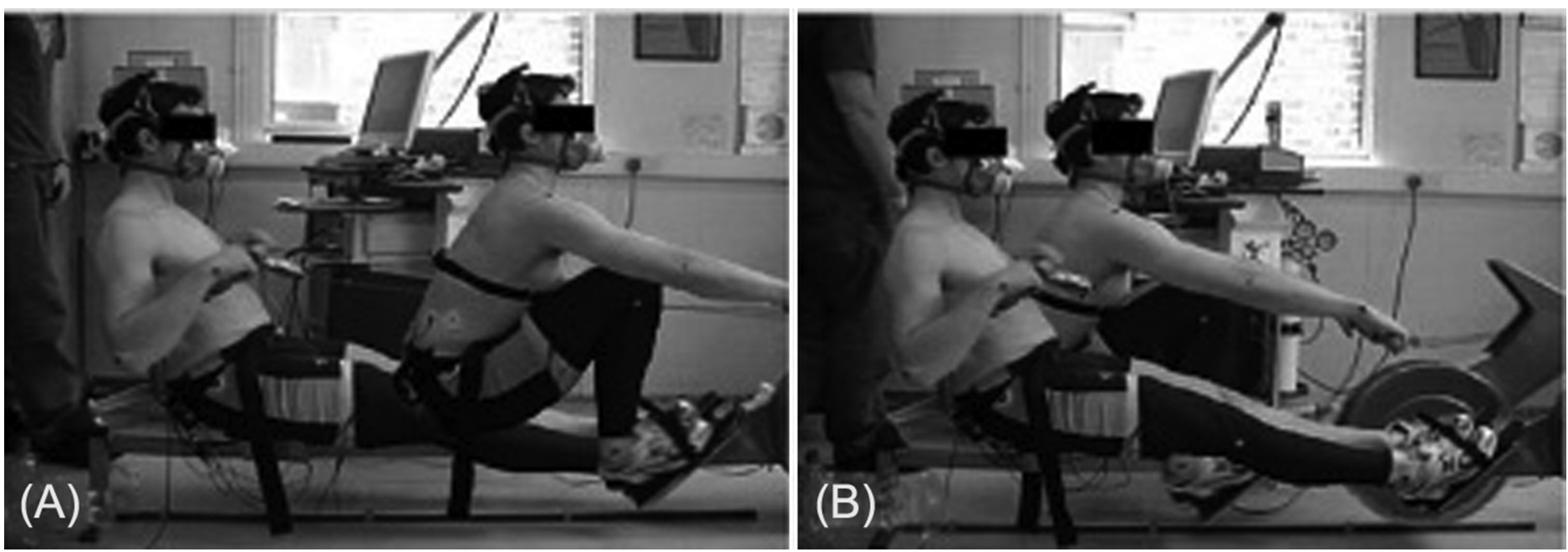

Figure 1 - A rower exercising on a RowPerfect ergometer in both a fixed (A) and a dynamic (B) condition. Note the change in body and flywheel position between scenarios.

performed on different ergometer types could not be considered interchangeable. This is an important issue for rowing coaches, and one which has not yet been adequately addressed. Previous studies have compared only stationary and dynamic versions of the same ergometer device. Comparisons have been drawn between $\mathrm{C} 2$ stationary and sliding models, ${ }^{8}$ and between RowPerfect fixed and free mechanisms. ${ }^{10}$ However, no studies have directly compared responses across 2 inherently different device types (namely $\mathrm{C} 2$ vs RowPerfect). Considering the availability of these 2 ergometer designs and the likelihood of athletes using them interchangeably, it is important for practitioners to be aware of any potential differences in physiological response between them.

The aim of the current study was therefore to directly compare physiological responses during GXT performed on the 2 most common commercially available rowing ergometers (C2 and RowPerfect 3 [RP3]). Based on previous studies, it was hypothesized that no significant differences would occur at any exercise intensity. ${ }^{9,10}$ It is intended that information gained from the current study might be used by athletes and coaches to determine the equivalence of different ergometer types for the purposes of laboratory-based testing and training prescription.

\section{Methodology}

\section{Study Design}

This was a repeated-measures observational study comparing physiological responses to GXT on dynamic (RP3) and stationary (C2) rowing ergometers. An a-priori power test was undertaken, and based on a repeated-measures analysis of variance design, a moderate effect size of 0.25 , a critical alpha of .05 , and power of 0.95 , it was determined that a minimum of 18 participants were required. A cohort of 23 subelite male rowers $(n=23)$ were subsequently recruited from 3 local clubs. Range of rowing experience for the group was 1 to 14 years. Participants were asked to provide a recent performance indicator on the preparticipation screening form. Based on the phase of the season, the most commonly reported indicator was 6-km single-scull time-trial performance $(\mathrm{n}=17$ out of 23$)$. The mean (SD) for 6-km time trial was $21.0(0.9)$ minutes. Inclusion criteria included prior experience with both ergometer types and fitness to perform maximal exercise. Exclusion criteria included significant illness or injury in the previous 3 months and taking medications, which alter cardiorespiratory response to exercise. The study conformed to the Declaration of Helsinki and received institutional review board approval from the Trinity College Faculty of Health Sciences Research Ethics Committee.

\section{Test Protocol}

Each participant performed a GXT to volitional exhaustion on each ergometer type. The order of testing was randomized. Tests were performed a minimum of 2 and maximum of 7 days apart to allow adequate recovery. Repeat testing was performed at the same time of day \pm 1 hour to minimize circadian variability. Participants were instructed to avoid strenuous exercise, alcohol, or caffeine in the 24 hours prior to testing. They were advised to arrive in a fully fueled and hydrated state. Identical instructions were issued prior to each test to replicate conditions.

Prior to the first GXT, participants were familiarized with testing procedures and informed consent was obtained. A medical evaluation, including recording of resting blood pressure and HR, was performed. Pulmonary function testing and venous blood sampling were also conducted. Blood samples were analyzed using an automated cell counter system (Coulter Electronics, Buckinghamshire, United Kingdom) for white blood cell count and differential, red blood cell count, hematocrit $(\%)$ and hemoglobin concentration $\left(\mathrm{g} \cdot \mathrm{dL}^{-1}\right)$. The finding of an elevated white blood cell count in combination with signs or symptoms of underlying illness were grounds for exclusion. Height and body mass were measured using a stadiometer (Holtain Ltd, Dyfed, United Kingdom) and precalibrated counter-balancing weighing scales (Seca $\mathrm{GmBH}$, Hamburg, Germany), respectively. Percentage body fat was estimated using a Harpenden skinfold caliper (Baty International, West Sussex, United Kingdom) and the 4-site estimation equation to allow for calculation of lean body mass. ${ }^{12}$

Participants completed a standardized 10-minute warm-up consisting of 4 minutes at $120 \mathrm{~W}, 3$ minutes at $150 \mathrm{~W}$ and 3 minutes at $120 \mathrm{~W}$. SR was self-selected and no test data were collected during the warm-up. For the $\mathrm{C} 2$, the damper was set to reflect a drag factor of $130 \mathrm{~W}$. Due to using an older version of RP3 software, 
drag factor settings were those most comfortable for the participant based on prior experience with the RP3. The GXT protocol consisted of 3-minute exercise bouts interspersed with a 1-minute interval for blood sampling. The initial workload was $120 \mathrm{~W}$, which then increased in $30 \mathrm{~W}$ increments for each stage. The participant was instructed to maintain an average power output as close as possible $( \pm 5 \mathrm{~W})$ to the target for each interval. Continuous feedback on target power output was provided.

Test termination criteria were as follows:

- Volitional exhaustion-participant unable to continue rowing and/or requests that the test be stopped despite verbal encouragement to continue.

- Plateau in $\mathrm{HR}$ and $\mathrm{VO}_{2}$ despite increasing workload.

- Inability to maintain target workload.

The endpoint criterion for achieving maximal exercise was peak blood lactate concentration $\left(\mathrm{BLa}_{\max }\right)$ greater than $9.0 \mathrm{mmol} \cdot \mathrm{L}^{-1} \cdot{ }^{13}$

\section{Data Collection}

Cardiorespiratory data were collected continuously using cardiopulmonary exercise testing (CPET; COSMED, Rome, Italy) breath-bybreath metabolic analyzer cart. After the warm-up, each participant was fitted for a silicone V2 facemask (Hans Rudolph, Shawnee, KS). HR data were recorded continuously via the CPET software using a TP5 CardioSport HR monitor (CardioSport, Taipei, Taiwan). Capillary blood samples were drawn from the earlobe during each 1-minute stationary sampling period. A $25-\mu \mathrm{L}$ blood sample was injected into a YSI 1500 Sport analyzer (Yellow Springs Instruments, Yellow Springs, $\mathrm{OH}$ ), and BLa was recorded to the nearest $0.1 \mathrm{mmol} \cdot \mathrm{L}^{-1}$. The YSI analyzer was calibrated prior to each test, using a $5 \mathrm{mmol} \cdot \mathrm{L}^{-1}$ standard solution. SR was visually recorded from the ergometer visual display unit at 15 -second intervals and averaged over the final minute of each increment.

\section{Data Processing}

Mean HR (beats $\left.\mathrm{min}^{-1}\right), \mathrm{VO}_{2}\left(\mathrm{~mL} \cdot \mathrm{kg}^{-1} \cdot \mathrm{min}^{-1}\right), \mathrm{VE}\left(\mathrm{L} \cdot \mathrm{min}^{-1}\right)$, and SR (strokes. $\mathrm{min}^{-1}$ ) during the final minute of each stage were calculated. Graphs of workload (W) versus HR, BLa, and $\mathrm{VO}_{2}$ were plotted via third-order polynomial curve fitting. Anaerobic threshold was identified using the $\mathrm{D}_{\max }$ method via customized programs (MATLAB, version 9.7.0; MathWorks, Natick, MA). This method involves identifying the maximal perpendicular distance from a line drawn between the first and last exercise BLa data points and a third-order polynomial curve representing BLa data. ${ }^{14}$ The corresponding load, $\mathrm{HR}$, and $\mathrm{VO}_{2}$ at $\mathrm{D}_{\max }$ were then interpolated (see Figure 2). Maximum workload $\left(\mathrm{P}_{\max }\right)$ was defined as the final 3 -minute interval completed to within $\pm 10 \mathrm{~W}$ of the target output.

\section{Statistical Analysis}

Test data (HR, BLa, VE, $\mathrm{VO}_{2}$, and $\mathrm{SR}$ ) at $\mathrm{P}_{\max }$, at $\mathrm{D}_{\max }$, and at fixed workloads of 120,150,180, 210, 240, 270, and $300 \mathrm{~W}$ were tabulated and presented as group mean (SD). All statistical analyses were performed using GraphPad Prism (version 9.0.0; GraphPad Software, San Diego, CA). Data sets were evaluated for normality using Kolmogorov-Smirnov testing. All data sets were normally distributed. The effect of workload and ergometer condition was subsequently assessed using a 2-factor repeated-measures analysis of variance $(7 \times 2)$. Data at $\mathrm{P}_{\max }$ and $\mathrm{D}_{\max }$ were compared between ergometer conditions using paired Student $T$ tests. Critical alpha was adjusted for multiple pairwise comparisons using Bonferroni

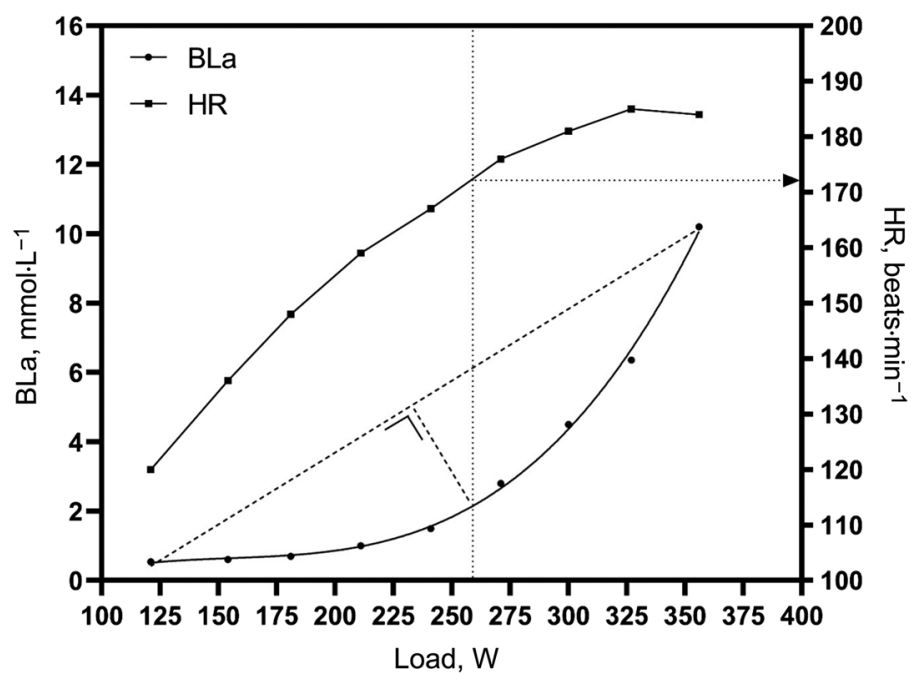

Figure 2 - BLa and HR response to incremental exercise. Dashed lines represent the calculation of $D_{\max }$. Dotted lines represent the interpolation of workload (vertical) and $\mathrm{HR}$ (horizontal) at $\mathrm{D}_{\max }$. $\mathrm{BLa}$ and $\mathrm{VO}_{2}$ at $\mathrm{D}_{\max }$ were interpolated in a similar fashion. BLa indicates blood lactate; HR, heart rate; $\mathrm{VO}_{2}$, oxygen consumption.

corrections, with $P$ set at .05 throughout. Statistically significant differences identified were further analyzed using a post hoc analysis of covariance model with $\mathrm{SR}$ as the fixed covariate. Finally, Bland-Altman analyses with $95 \%$ limits of agreement (95\% LoA) were used to assess agreement between ergometer design for indices measured at $\mathrm{D}_{\max }$ (load, $\mathrm{HR}, \mathrm{VO}_{2}$, and $\mathrm{BLa}$ ). For the purposes of comparing the agreement between ergometers, acceptable $95 \%$ LoAs were set at $13 \mathrm{~W}$ for load at $\mathrm{D}_{\max },{ }^{15} 3$ beats $\cdot \mathrm{min}^{-1}$ for $\mathrm{HR}$ at $\mathrm{D}_{\max }, 2 \mathrm{~mL} \cdot \mathrm{kg}^{-1} \cdot \mathrm{min}^{-1}$ for $\mathrm{VO}_{2}$ at $\mathrm{D}_{\max }$, and $0.4 \mathrm{mmol} \cdot \mathrm{L}^{-1}$ for BLa at $\mathrm{D}_{\max } \cdot{ }^{16}$ These criterion LoA for assessed variables were derived from published test-retest reliability for Functional Threshold Power in cyclists, ${ }^{15}$ and interdevice agreement between Lactate Pro 2 analyzers during a parallel incremental testing study in the same cohort of rowers. ${ }^{16}$

\section{Results}

\section{Demographic Information and Anthropometric Data}

The mean age of the group was 20 (2.5) years, range 16 to 28 years. Mean duration of rowing experience was 5 (3) years, range 1 to 14 years. Mean (SD) anthropometric data for the group are presented in Table 1. A total of 46 GXT were completed ( 2 tests for each of 23 participants).

\section{Comparison of Physiological Variables at Maximal Intensity}

Mean data for $\mathrm{P}_{\max }$ were 347 (27) and 351 (28) W on the $\mathrm{C} 2$ and $\mathrm{RP} 3$, respectively. A comparison of test data (mean [SD]) across both ergometer types at maximal intensity is presented in Table 2 . Using Kolmogorov-Smirnov normality tests, all maximal and threshold data were normally distributed. Multiple paired Student $T$ tests, with corrections, were used to compare $\mathrm{VO}_{2}$ peak, $\mathrm{VE}_{\text {peak }}$, $\mathrm{HR}_{\max }, \mathrm{BLa}_{\max }, \mathrm{P}_{\max }$, and $\mathrm{SR}_{\max }$ responses to $\mathrm{C} 2$ and $\mathrm{RP} 3$ ergometer tests. No significant differences were detected in $\mathrm{VO}_{2}$ peak $(T=1.699, P>.05), \quad \mathrm{HR}_{\max }(T=.514, P>.05), \quad \mathrm{P}_{\max }$ 
$(T=1.141, P>.05)$, or $\mathrm{BLa}_{\max }(T=1.026, P>.05)$. However, $\mathrm{VE}_{\text {peak }}$ was significantly higher for the RP3 $(T=2.943, P<.05)$, with a small effect size of $d=0.43$. $\mathrm{SR}_{\max }$ data were also higher for the RP3 $(T=7.904, P<.05)$, with a large effect size of $d=1.64$.

\section{Comparison of Physiological Variables at Anaerobic Threshold}

$\mathrm{VO}_{2}, \mathrm{HR}, \mathrm{BLa}$, and workload at anaerobic threshold were identified using the $\mathrm{D}_{\max }$ method. Multiple paired Student $T$ tests, with corrections, were used to compare $\mathrm{VO}_{2}, \mathrm{HR}, \mathrm{BLa}$, and load at $\mathrm{D}_{\text {max }}$. These data are presented in Table 3. No significant differences were detected for load $(T=1.438, P>.05), \mathrm{HR}(T=1.553, P>.05), \mathrm{BLa}(T=.261$, $P>.05)$, or $\mathrm{VO}_{2}(T=2.509, P>.05)$ at $\mathrm{D}_{\max }$. Bland-Altman plots (see Figure 3 ) demonstrated wide $95 \%$ LoA for load ( +34 and $-25 \mathrm{~W})$, $\mathrm{HR}\left(+9\right.$ and -13 beats $\left.\cdot \mathrm{min}^{-1}\right), \mathrm{VO}_{2}\left(+4.9\right.$ and $\left.-2.9 \mathrm{~mL} \cdot \mathrm{kg} \cdot \mathrm{min}^{-1}\right)$, and $\mathrm{BLa}\left(+1.1\right.$ and $\left.-1.1 \mathrm{mmol} \cdot \mathrm{L}^{-1}\right)$ at $\mathrm{D}_{\max }$.

\section{Analysis of Data Across Standard Workloads}

$\mathrm{HR}, \mathrm{VO}_{2}, \mathrm{BLa}$, and $\mathrm{SR}$ data for each interval on each ergometer type are provided in Table 4. The $300 \mathrm{~W}$ was the highest increment successfully completed by all participants on both ergometer types ( $\mathrm{n}=20$ participants completed $330 \mathrm{~W}, \mathrm{n}=13$ completed $360 \mathrm{~W}$, and $\mathrm{n}=2$ completed $390 \mathrm{~W}$ ). Workload had a significant effect on all variables using 2-factor repeated-measures analysis of variance across all increments from 120 to $300 \mathrm{~W}$ (see Figure 3). $\mathrm{VO}_{2}$ and BLa data both significantly increased with workload $(F=913.5, P<.001$, $\eta^{2}=.79$ and $F=139.3, P<.001, \eta^{2}=.72$, respectively), with no significant differences observed between ergometer types for either variable. HR and SR data also significantly increased with workload $\left(F=737, P<.001, \eta^{2}=.78\right.$ and $F=612.4, P<.001, \eta^{2}=.82$, respectively). However, ergometer design had a significant effect on both HR and SR response $\left(F=4.383, P<.05, \eta^{2}<.001\right.$ and $F=56.7$, $P<.001, \eta^{2}=.03$, respectively) with both variables consistently higher on the RP3. Post hoc analysis highlighted significantly higher HR response comparing RP3 to C2, specifically at $210 \mathrm{~W}$ (164 [8] vs 161 [10] beats $\cdot \mathrm{min}^{-1}, P<.05, d=0.32$ ) and $240 \mathrm{~W}$ (173 [8] vs 169 [9] beats $\left.\cdot \min ^{-1}, P<.05, d=0.47\right)$. SR was significantly higher on the RP3 at all workloads $(P<.05, d=0.60$ at $120 \mathrm{~W}$ and $P<.001$, $d=0.95$ at all other workloads). A significant (workload by ergometer) interaction effect was also observed within SR $(F=3.48, P<.01)$, suggesting that ergometer design influenced the changes in SR associated with workload.

\section{Discussion}

The purpose of the current study was to compare physiological responses of a group of subelite male rowers during laboratory-based GXT performed on stationary (C2) and dynamic (RP3) ergometers. It

Table 1 Anthropometric Data of All Participants $(\mathrm{N}=23)$

\begin{tabular}{|c|c|c|c|c|c|}
\hline & Height, m & Body mass, kg & BMI, $\mathrm{kg} \cdot \mathrm{m}^{-2}$ & Body fat, \% & LBM, kg \\
\hline Mean & 1.88 & 82.0 & 23.2 & 13 & 71.4 \\
\hline SD & 0.06 & 8.8 & 1.6 & 3 & 6.9 \\
\hline
\end{tabular}

Abbreviations: BMI, body mass index; LBM, lean body mass.

Table 2 Comparison of Physiological Variables (Mean [SD]) at Maximal Intensity

\begin{tabular}{lcccc}
\hline Variable & Concept2 & RowPerfect3 & $\boldsymbol{P}$ & $\boldsymbol{T}$ \\
\hline $\mathrm{VO}_{2}$ peak, $\mathrm{mL} \cdot \mathrm{kg}^{-1} \cdot \mathrm{min}^{-1}$ & $59.5(5.8)$ & $58.2(6.6)$ & .103 & 1.699 \\
$\mathrm{HR}_{\max }$, beats$\cdot \mathrm{min}^{-1}$ & $195(7)$ & $196(7)$ & .612 & .514 \\
$\mathrm{BLa}_{\text {max }}, \mathrm{mmol} \cdot \mathrm{L}^{-1}$ & $10.1(2.2)$ & $9.6(2.0)$ & .316 & 1.026 \\
$\mathrm{VE}_{\text {peak }}, \mathrm{L} \cdot \mathrm{min}^{-1}$ & $181.5^{*}(17.1)$ & $188.9(17.6)$ & .008 & 2.943 \\
$\mathrm{P}_{\text {max }}, \mathrm{W}$ & $347(27)$ & $351(28)$ & .266 & 1.141 \\
$\mathrm{SR}_{\text {max }}$, strokes$\cdot \mathrm{min}^{-1}$ & $30 *(2)$ & $34(2)$ & $<.001$ & 7.904 \\
\hline
\end{tabular}

Abbreviations: $\mathrm{BLa}_{\max }$, maximal blood lactate; $\mathrm{HR}_{\max }$, maximal heart rate; $\mathrm{P}_{\max }$, maximum workload; $\mathrm{SR}_{\max }$, maximal stroke rate; $\mathrm{VE}_{\text {peak }}$, peak minute ventilation; $\mathrm{VO}_{2}$ peak, peak oxygen consumption.

*Statistically significant difference between ergometers at $P<.05$.

Table 3 Comparison of Physiological Variables (Mean [SD]) at Anaerobic Threshold $\left(D_{\max }\right)$

\begin{tabular}{lcccc}
\hline Variable & Concept2 & RowPerfect3 & $\boldsymbol{P}$ & $\boldsymbol{T}$ \\
\hline $\mathrm{VO}_{2}, \mathrm{~mL} \cdot \mathrm{kg}^{-1} \cdot \mathrm{min}^{-1}$ & $50.0(5.4)$ & $49.0(5.3)$ & .66 & 2.509 \\
Fractional $\mathrm{VO}_{2}, \%$ of $\mathrm{VO}_{2}$ peak & $84.1(3.6)$ & $84.3(3.5)$ & .20 & .208 \\
$\mathrm{HR}$, beats $\cdot \mathrm{min}^{-1}$ & $173(7)$ & $175(6.8)$ & .89 & 1.553 \\
Fractional HR, \% of $\mathrm{HR}_{\max }$ & $88.8(3)$ & $89.5(2.4)$ & .85 & 1.272 \\
$\mathrm{BLa}, \mathrm{mmol} \cdot \mathrm{L}^{-1}$ & $2.5(0.6)$ & $2.5(0.6)$ & .17 & .261 \\
Load, W & $254(18)$ & $250(22)$ & .75 & 1.438 \\
\hline Abbreviations: BLa, blood lactate; $\mathrm{HR}$, heart rate; $\mathrm{HR}_{\text {max }}$, maximal $\mathrm{HR} ; \mathrm{VO}_{2}$, oxygen consumption; $\mathrm{VO}_{2}$ peak, peak $\mathrm{VO}_{2}$.
\end{tabular}


Workload

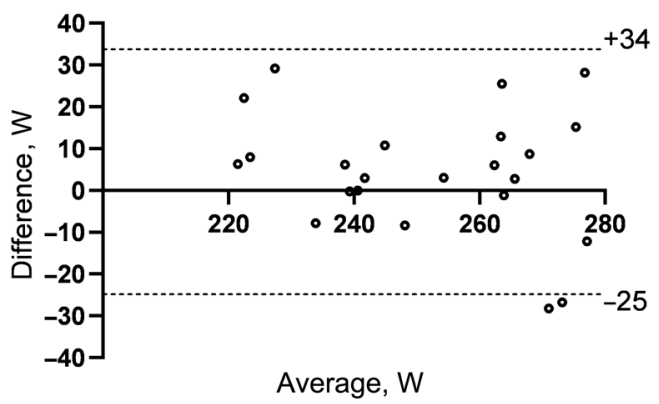

$\mathrm{VO}_{2}$

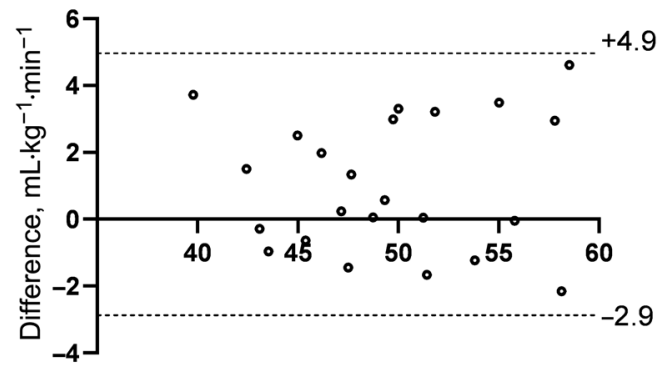

Average, $\mathrm{mL} \cdot \mathrm{kg}^{-1} \cdot \mathrm{min}^{-1}$
HR

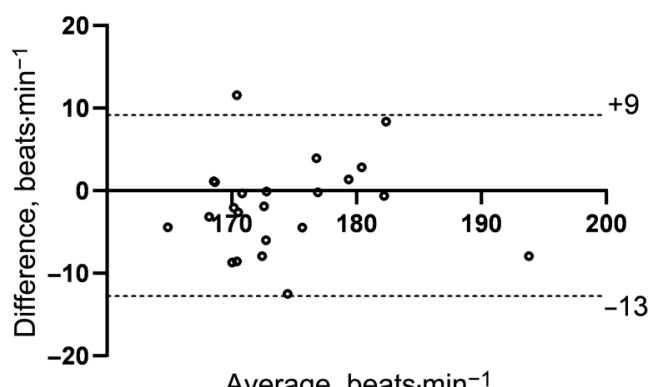

BLa

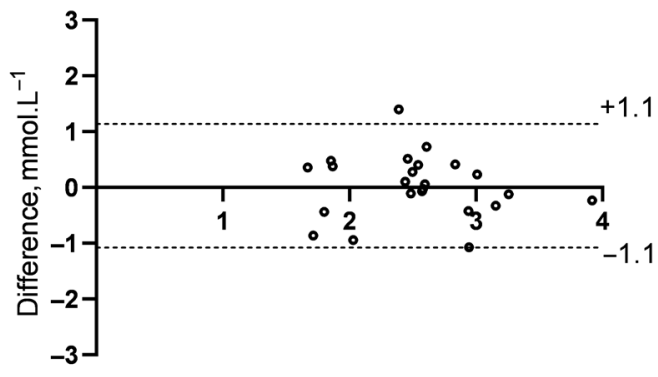

Average, $\mathrm{mmol} \cdot \mathrm{L}^{-1}$

Figure 3 - Bland-Altman plots for load, $\mathrm{HR}, \mathrm{VO}_{2}$, and $\mathrm{BLa}$ at $\mathrm{D}_{\max }$ for both ergometer types. 95\% LOA presented in lightly dashed lines upper and lower lines. Mean bias presented in heavier dashed central line. BLa indicates blood lactate; HR, heart rate; $\mathrm{VO}_{2}$, oxygen consumption; $95 \% \mathrm{LOA}$, $95 \%$ limits of agreement.

Table 4 Mean (SD) $\mathrm{VO}_{2}$, HR, BLa, and SR Data for All Intervals on C2 and RP3 Ergometers

\begin{tabular}{|c|c|c|c|c|c|c|c|c|}
\hline \multirow[b]{2}{*}{ Power output, W } & \multicolumn{2}{|c|}{$\mathrm{VO}_{2}, \mathrm{~mL} \cdot \mathrm{kg}^{-1} \cdot \mathrm{min}^{-1}$} & \multicolumn{2}{|c|}{ HR, beats $\cdot \min ^{-1}$} & \multicolumn{2}{|c|}{ BLa, mmol.L ${ }^{-1}$} & \multicolumn{2}{|c|}{ SR, strokes.min ${ }^{-1}$} \\
\hline & $\mathrm{C} 2$ & RP3 & $\mathrm{C} 2$ & RP3 & $\mathrm{C} 2$ & RP3 & C2 & RP3 \\
\hline 120 & $31.0(2.4)$ & $30.9(3.3)$ & $131(12)$ & $132(10)$ & $0.6(0.1)$ & $0.7(0.2)$ & $17(2)$ & $17(2)$ \\
\hline 150 & $35.5(3.2)$ & $35.4(3.0)$ & $143(11)$ & $143(10)$ & $0.6(0.2)$ & $0.7(0.2)$ & $18(1)$ & $19(1)$ \\
\hline 180 & $40.2(3.9)$ & $39.8(3.7)$ & $153(12)$ & $153(10)$ & $0.9(0.3)$ & $1.0(0.3)$ & $20(1)$ & $21(2)$ \\
\hline 210 & $44.3(4.5)$ & $42.7(7.7)$ & $162(11)$ & $164(8)$ & $1.4(0.6)$ & $1.5(0.5)$ & $21(1)$ & $23(2)$ \\
\hline 240 & $48.2(5.4)$ & $47.7(4.4)$ & $171(10)$ & $173(8)$ & $2.2(0.9)$ & $2.3(0.9)$ & $23(2)$ & $25(2)$ \\
\hline 270 & $51.7(5.0)$ & $51.0(4.6)$ & $178(9)$ & $180(8)$ & $3.6(1.5)$ & $3.5(1.3)$ & $25(2)$ & $27(2)$ \\
\hline 300 & $54.4(5.1)$ & $53.7(5.2)$ & $184(8)$ & $186(8)$ & $5.6(2.3)$ & $5.4(2.0)$ & $27(2)$ & $30(2)$ \\
\hline $330^{\mathrm{a}}$ & $56.8(5.0)$ & $55.7(6.2)$ & $188(10)$ & $190(8)$ & $8.0(2.7)$ & $7.4(2.6)$ & $29(2)$ & $32(1)$ \\
\hline $360^{\mathrm{b}}$ & $58.0(4.8)$ & $57.3(6.5)$ & $191(4)$ & $191(6)$ & $9.5(3.1)$ & $8.7(2.5)$ & $30(2)$ & $34(2)$ \\
\hline $390^{\mathrm{c}}$ & $55.7(7.9)$ & $52.2(4.0)$ & $192(6)$ & $191(5)$ & $7.2(0.2)$ & $8.3(1.8)$ & $29(1)$ & $36(1)$ \\
\hline
\end{tabular}

Abbreviations: BLa, blood lactate; $\mathrm{C} 2$, Concept2; HR, heart rate; RP3, RowPerfect3; SR, stroke rate; $\mathrm{VO}_{2}$, oxygen consumption.

${ }^{a} \mathrm{n}=20$ fully completed all intervals up to and including $330 \mathrm{~W}$ on both ergometers. ${ }^{b} \mathrm{n}=13$ fully completed all intervals up to and including $360 \mathrm{~W}$ on both ergometers.

${ }^{c} \mathrm{n}=2$ fully completed all intervals up to and including $390 \mathrm{~W}$ on both ergometers.

was hypothesized that no significant differences would occur at any exercise intensity. ${ }^{10}$ Although some differences were observed, namely HR at discrete workloads and ventilatory data (VE) at maximal intensity, these physiological differences were the result of the consistently higher stroke rates performed on the dynamic ergometer (RP3). This biomechanical difference in SR did not result in significant differences in anaerobic threshold data $\left(D_{\max }\right)$ between ergometer designs. However, poor levels of agreement between ergometers for $\mathrm{D}_{\max }$ derived data suggest that the direct application of test results from one ergometer design to training prescription on the other cannot be recommended.

\section{Maximal Physiological Responses}

No significant differences in $\mathrm{HR}_{\max }\left(195\right.$ [7] vs 196 [7] beats $\mathrm{min}^{-1}$ ), $\mathrm{VO}_{2}$ peak $\left(59.5\right.$ [5.8] vs 58.2 [6.6] $\mathrm{mL} \cdot \mathrm{kg}^{-1} \cdot \mathrm{min}^{-1}$ ) or $\mathrm{BLa}_{\max }$ (10.1 [2.2] vs 9.6 [2.0] $\left.\mathrm{mmol} \cdot \mathrm{L}^{-1}\right)$ responses were observed between C2 or RP3 conditions. These findings agree with previous studies 
comparing maximal physiological responses to GXT in stationary versus dynamic ergometry. ${ }^{9,10}$

$\mathrm{VE}_{\text {peak }}$ was significantly higher for dynamic compared with stationary ergometry (189 [18] vs 182 [17] $\mathrm{L} \cdot \mathrm{min}^{-1}$ for RP3 and $\mathrm{C} 2$, respectively). Comparison of this finding with the existing literature is limited by the sparsity of studies reporting VE data as an outcome measure. As with all physiological variables examined, Mahony et al ${ }^{10}$ observed no significant differences in VE data at any exercise intensity. However, their comparison involved the use of an RP3 design for both stationary and dynamic rowing ergometry, and is therefore not directly comparable.

The technique of ventilatory and locomotor coupling likely account for the observed difference in $\mathrm{VE}_{\text {peak }} \cdot{ }^{17}$ This involves entrainment of breathing pattern to the rowing stroke and is believed to support the complex role of the respiratory muscles in facilitating ventilation and stabilizing the thorax. Accordingly, an increase in VE would be expected to parallel increases in SR. Indeed, when SR was fixed as a covariate, no significant differences in $\mathrm{VE}_{\text {peak }}$ were observed in the current study, further supporting the conclusion that this difference was SR-related. Mahony et al $^{10}$ reported no differences in either SR or VE at maximal intensity, further supporting the impact of SR on ventilatory response in rowing.
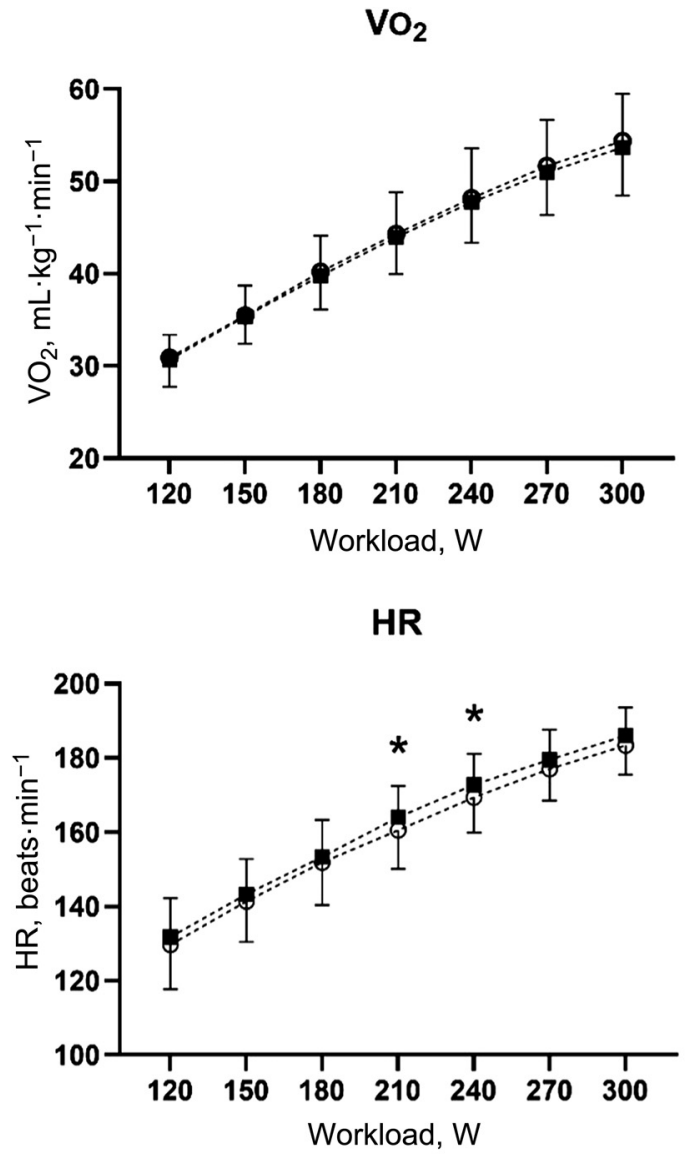

\section{Submaximal Physiological Responses}

No significant differences in mean HR response at $\mathrm{D}_{\max }(173$ [7] vs 175 [6.8] beats $\left.\cdot \min ^{-1}\right)$ or in fractional HR at $\mathrm{D}_{\max }(88.3 \%$ [3\%] vs $89.5 \%$ [2.4\%] of $\mathrm{HR}_{\max }$ ) were observed between conditions. As would be expected using a standard GXT protocol, HR increased with increasing load $(F=737, P<.001)$. In addition, ergometer type had a significant effect on HR response across workloads $(F=737, P<.05)$. At both 210 and $240 \mathrm{~W}$ intervals, significantly higher mean HR data were recorded for the RP3 (164 [8] vs 161 [10] beats $\cdot \mathrm{min}^{-1}, P<.05$ and 173 [8] vs 169 [9] beats $\cdot \min ^{-1}, P<.05$, respectively; see Figure 4$)$. This contrasts with data reported by Mahony et al ${ }^{10}$ in which no significant differences in submaximal HR responses were observed. More recently, Rossi et al ${ }^{11}$ did report increased mean HR response associated with dynamic ergometry at workloads corresponding to $60 \%$ and $70 \%$ of maximum load. Of note, the 2 workloads at which significant differences were observed in the current study, 210 and $240 \mathrm{~W}$, would correspond to intensities equivalent to $60 \%$ and $69 \%$ of $\mathrm{P}_{\max }$, respectively.

The effect of ergometer type on HR was accompanied by an increase in SR across workloads $(F=56.7, P<.001)$, with higher data for the RP3 at all intervals $(P<.05$ at $120 \mathrm{~W}, P<.001$ at all other workloads). This finding of higher SR associated with
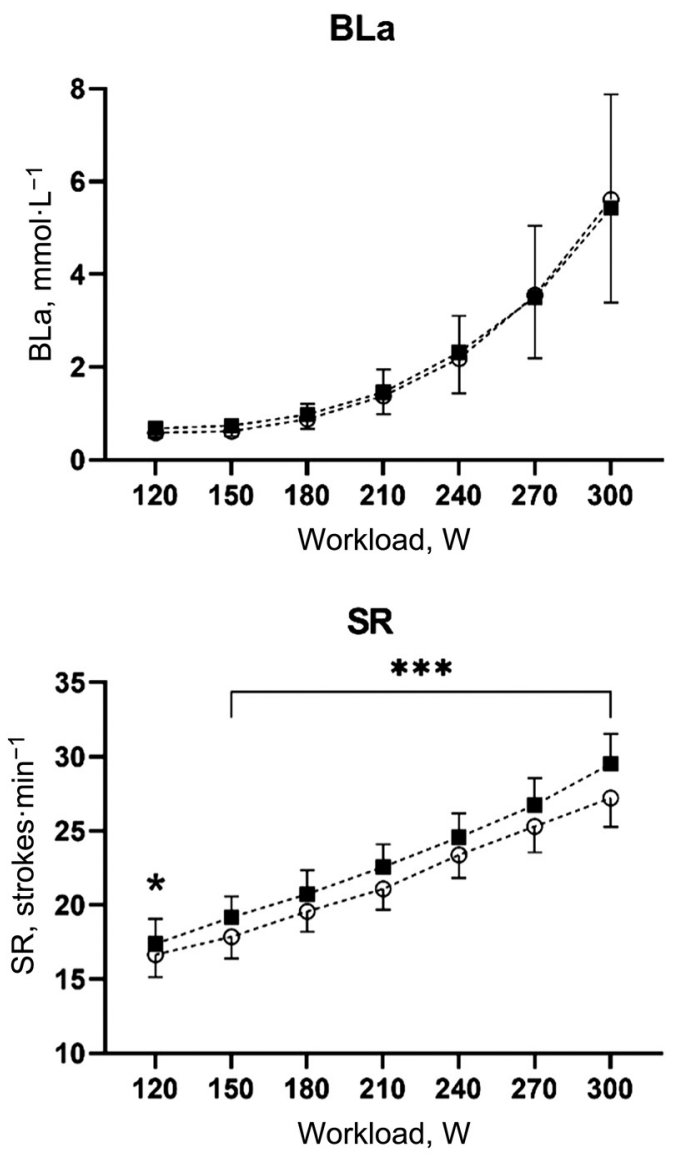

RowPerfect

Figure 4 - Group mean (SD) exercise response for $\mathrm{VO}_{2}, \mathrm{BLa}, \mathrm{HR}$, and SR across 7 workloads and 2 ergometer designs. Asterisks infer significant differences between ergometer designs at a specified workload $(* P<.05, * * * P<.001)$. BLa indicates blood lactate; $\mathrm{HR}$, heart rate; $\mathrm{SR}$, stroke rate; $\mathrm{VO}{ }_{2}$, oxygen consumption. 
dynamic ergometry has been described elsewhere ${ }^{8}$ and is typically associated with lower peak force generation. ${ }^{11}$ In previous studies, however, such biomechanical differences between stationary and dynamic ergometry were not associated with significant differences in physiological response. ${ }^{9}$ When SR was accounted for as a covariate, no significant differences in HR response were observed between ergometer design in the current study.

There were no significant differences in mean $\mathrm{VO}_{2}$ response at $\mathrm{D}_{\max }$ observed across the 2 conditions (50.0 [5.4] vs 49.0 [5.3] $\mathrm{mL} \cdot \mathrm{kg}^{-1} \cdot \mathrm{min}^{-1}$ for $\mathrm{C} 2$ and $\mathrm{RP} 3$, respectively) and no differences in fractional $\mathrm{VO}_{2}$ at $\mathrm{D}_{\max } 84.1 \%$ [3.6\%] vs $84.3 \%$ [3.5\%] of $\mathrm{VO}_{2}$ peak). When comparing across standard workloads, $\mathrm{VO}_{2}$ increased with increasing workload $(F=913.5, P<.001)$; however, no main effect of ergometer type on $\mathrm{VO}_{2}$ response was observed. Similarly, no differences in BLa were noted at $\mathrm{D}_{\max }(2.5$ [0.6] vs $2.5[0.6] \mathrm{mmol} \cdot \mathrm{L}^{-1}$ ) or at any standard workload. These data agree with findings reported previously by Mahony et al. ${ }^{10}$

To the best of our knowledge, this is the first study to directly compare physiological responses during incremental exercise on the 2 most common commercially available rowing ergometers. This is a novel approach in contrast with previous studies comparing stationary and dynamic versions of the same ergometer, 9,10 and may account for the discrepancy in findings. In addition, it has been suggested that potential differences in physiological responses across ergometer types may be less apparent in highly trained athletes. ${ }^{8}$ Both Mahony et $\mathrm{al}^{10}$ and Holsgaard-Larsen and Jensen ${ }^{9}$ recruited elite international-level rowers. This contrasts with the subelite collegiate-level rowers who participated in the current study. It is possible that any differences in physiological response to GXT would be more apparent in this less experienced cohort.

\section{Implications for Exercise Testing and Prescription}

The anaerobic threshold is widely used as a reference point for training prescription in rowers. ${ }^{18}$ This can be calculated using the $\mathrm{D}_{\max }$ method, which determines anaerobic threshold from the BLa curve. ${ }^{13}$ Physiological variables at $\mathrm{D}_{\max }$ are then interpolated to define individualized HR or load-based training zones.

As laboratory-based exercise testing and training prescription hinge on the measurement of physiological variables at anaerobic threshold, comparison of response profiles at this threshold is of greatest practical importance for the purpose of determining equivalence of ergometer types. As no significant differences in HR, $\mathrm{VO}_{2}, \mathrm{BLa}$, or load at $\mathrm{D}_{\max }$ were observed in the current study, it is tempting to suggest that training zones derived from GXT on one ergometer type could be applicable to an alternative device. However, the wide $95 \%$ LoA computed in the current study indicate poor agreement in $\mathrm{D}_{\max }$ derived data comparing ergometers. Caution should therefore be applied by practitioners in using these devices interchangeably.

\section{Study Limitations and Recommendations for Future Research}

Drawing direct comparisons with prior studies is limited by inconsistencies in defining key physiological parameters. Regarding metabolic data, selection of an appropriate sampling interval is essential for the meaningful interpretation of breath-by-breath $\mathrm{VO}_{2}$ data. ${ }^{19}$ In the current study, mean $\mathrm{VO}_{2}$ at each workload was calculated using data from the second half of each 3-minute interval. $\mathrm{VO}_{2}$ peak was then determined as the highest consecutive 5-breath average during the final stage of each test. ${ }^{15}$ Choice of sampling strategy is rarely reported on but can have a significant effect on determination of $\mathrm{VO}_{2}$ peak. ${ }^{20}$

A key underlying assumption in the current study was that both tests were performed under similar conditions. While the laboratory environment, time of testing and test protocols were held constant; however, not all variables were strictly controlled. Measures to ensure greater control of participant factors, such as assessment of hydration status with urine specific gravity, could have been implemented.

While a goal of the current study was to compare 2 inherently different ergometer devices, this could be considered a relative methodological weakness. Potential differences in power derivation between the 2 ergometer types, for example, were not investigated or controlled for. While previous studies have reported no such differences when comparing dynamic and stationary iterations of the same device, ${ }^{10}$ equivalence across different designs has, to date, not been demonstrated. The inability to control for drag factor on the RP3 is a significant limitation of the current study. However, previous studies investigating the impact of drag factor on physiological responses to GXT have produced conflicting results. While Kane et $\mathrm{al}^{21}$ reported only a small impact of drag factor on responses to maximal exercise, a more recent study did observe a significant effect of drag factor on $\mathrm{HR}$ response. ${ }^{22}$ Of note, however, no significant differences in $\mathrm{VO}_{2}$ or BLa responses were observed. It would, however, be useful to repeat this study with more rigorous control of ergometer resistance.

Sample size could be considered a relative strength of the current study. The recruitment of 23 rowers compares favorably with previous studies reporting sample sizes in the order of $8^{11}$ to $10^{10}$ participants. In addition, all participants successfully completed both tests with a $0 \%$ attrition rate. This sample can be considered representative of the population of Irish subelite male rowers; however, the scope for generalizing findings beyond this cohort is unknown. Additional studies incorporating alternative participant groups, for example female rowers, are warranted.

\section{Conclusions}

Laboratory-based exercise testing often forms the cornerstone of individualized training prescription for endurance athletes. In the case of rowing, the stationary $\mathrm{C} 2$ device has long been the favored ergometer type. More recently, the use of dynamic ergometers, such as the RP3, has increased due to purported benefits; namely, greater training specificity and reduced risk of some chronic overuse injuries. It is possible that some athletes may incorporate use of both devices in their training. It is therefore important for practitioners to know whether physiological responses to exercise are closely matched between these 2 ergometer types. The findings of the current study indicate minor differences in physiological responses, namely increased HR at discrete workloads and increased VE at maximal exercise, in favor of dynamic ergometry. These minor physiological differences appear to be the result of SR changes between devices. While no significant differences were observed in the estimation of anaerobic threshold, wide LoA suggests weak agreement between ergometers for the derivation of individualized training zones. It is therefore concluded that GXT-derived training prescriptions should be ergometer specific and coaches should exercise caution applying test data from one device to the prescription of anaerobic threshold training on the other. 


\section{References}

1. Elliott B, Lyttle A, Birkett O. The RowPerfect ergometer: a training aid for on-water single scull rowing. Sports Biomech. 2002;1(2):123134. doi:10.1080/14763140208522791

2. Vogler AJ, Rice AJ, Gore CJ. Physiological responses to ergometer and on-water incremental rowing tests. Int Sports Physiol Perform. 2010;5(3):342-358. doi:10.1123/ijspp.5.3.342

3. Secher NH. Rowing. In: Reilly T, Secher N, Snell P, Williams C, eds. Physiology of Sports. Spon; 1990:259-285.

4. Rekers CJN. Verification of the ROWPERFECT ergometer. Paper presented at: the A.R.A Senior Rowing Conference; October 2, 1993. London.

5. Fleming N, Donne B, Mahony N. A comparison of electromyography and stroke kinematics during ergometer and on-water rowing. $J$ Sports Sci. 2014;32:1127-1138.

6. Kleshnev V. Comparison of on-water rowing with its simulation on Concept 2 and RowPerfect machines. Paper presented at: 23rd International Symposium on Biomechanics in Sport; 2005. Beijing, China.

7. Bernstein IA, Webber O, Woledge RC. An ergonomic comparison of rowing machine designs: possible implications for safety. Br J Sports Med. 2002;36(2):108-112. doi:10.1136/bjsm.36.2.108

8. Benson A, Abendroth J, King D, Swensen T. Comparison of rowing on a concept 2 stationary and dynamic ergometer. J Sport Sci Med. 2011;10:267-273.

9. Holsgaard-Larsen A, Jensen K. Ergometer rowing with and without slides. Int J Sports Med. 2010;31(12):870-874. doi:10.1055/s-00301265148

10. Mahony N, Donne B, O'Brien M. A comparison of physiological responses to rowing on friction-loaded and air-braked ergometers. $J$ Sport Sci. 1999;17(2):143-149. doi:10.1080/026404199366244

11. Rossi J, Piponnier E, Vincent L, Samozino P, Messonnier L. Influence of ergometer design on physiological responses during rowing. Int J Sports Med. 2015;36(11):947-951. doi:10.1055/s0035-1548810
12. Durnin JV, Womersley J. Body fat assessed from total body density and its estimation from skinfold thickness: measurements on 481 men and women aged from 16 to 72 years. Br J Nutr. 1974;32(1):77-97. doi:10.1079/BJN19740060

13. Edvardsen E, Hem E, Anderssen SA. End criteria for reaching maximal oxygen uptake must be strict and adjusted to sex and age: a cross-sectional study. PLoS One. 2014:9(1):e85276. doi:10. 1371/journal.pone.0085276

14. Cheng B, Kuipers H, Snyder AC, Keizer HA, Jeukendrup A, Hesselink M. A new approach for the determination of ventilatory and lactate thresholds. Int J Sports Med. 1992;13(7):518-522. doi:10. 1055/s-2007-1021309

15. McGrath E, Mahony N, Fleming N, Donne B. Is the FTP test a reliable, reproducible and functional assessment tool in highly-trained athletes? Int J Exerc Sci. 2019;12:1334-1345.

16. Crotty NM, Boland M, Mahony N, Donne B, Fleming N. Reliability and validity of the lactate pro 2 analyzer. Meas Phys Educ Exerc Sci. 2021;25(3):202-211. doi:10.1080/1091367X.2020.1865966

17. Shephard RJ. Science and medicine of rowing: a review. J Sports Sci. 1998;16(7):603-620. doi:10.1080/026404198366416

18. Steinacker JM. Physiological aspects of training in rowing. Int $J$ Sports Med. 1993;14(suppl 1):S3-S10.

19. Whipp BJ, Ward SA, Lamarra N, Davis JA, Wasserman K. Parameters of ventilatory and gas exchange dynamics during exercise. $J \mathrm{Appl}$ Physiol. 1982;52(6):1506-1513. doi:10.1152/jappl.1982.52.6.1506

20. Hill DW, Stephens LP, Blumoff-Ross SA, Poole DC, Smith JC. Effect of sampling strategy on measures of $\mathrm{VO}_{2}$ peak obtained using commercial breath-by-breath systems. Eur J Appl Physiol. 2003; 89(6):564-569. doi:10.1007/s00421-003-0843-1

21. Kane DA, Jensen RL, Williams SE, Watts PB. Effects of drag factor on physiological aspects of rowing. Int J Sports Med. 2008;29(5): 390-394. doi:10.1055/s-2007-965333

22. Kane DA, MacKenzie SJ, Jensen RL, Watts PB. Effects of stroke resistance on rowing economy in club rowers post-season. Int J Sports Med. 2013;34:131-137. 